NOTE

\title{
Natural mortality and spatial patchiness: reply to Gulland
}

\author{
Michael D. McGurk \\ Envirocon Pacific Ltd., 205-2250 Boundary Road, Burnaby, British Columbia V5M 3Z3, Canada
}

\begin{abstract}
The daily natural mortality of marine pelagic organisms ranging in size from bacteria to whales scales with weight to the power -0.301 . This exponent is significantly lower than those for fish, -0.397 , and for pelagic crustaceans, -0.537 . The difference may reflect the action of secondary ecological factors within taxa. Spatial patchiness is one secondary factor that explains a significant amount of the variation in natural mortality of pelagic fish eggs and earlystage larvae. The relationship remains significant if the weight exponent used to standardize mortality for size is changed from an ecosystem value of -0.25 to a 'fish' value of -0.397 . To explain this observation, it is proposed that fish eggs and early-stage larvae are more vulnerable to predators when the embryos are aggregated in patches than when they are dispersed because these young fish lack the close-range antipredator behaviour that accompanies schooling in older fish. The effect on survival of the presence or absence of this component of schooling behaviour is not included in an earlier model of the relationship between predation and schooling.
\end{abstract}

Introduction. In a recent paper McGurk (1986b) proposed that natural mortality, $M$, of pelagic fish eggs and early-stage larvae was controlled primarily by their body size, $W$, and secondarily by their spatial patchiness, $p$, as measured by Lloyd's (1967) index. It was suggested that fish eggs and early-stage larvae are more vulnerable to predators than would be expected on the basis of their body size because they have not developed the motor skills and behaviour necessary to evade predators. Thus, patches of fish eggs and earlystage larvae produced by mass spawning and hatching may offer exceptional feeding opportunities to any predator that encounters them. The young fish should continue to suffer from heavy predation until the patches are dispersed by turbulent diffusion and until the larvae develop effective anti-predator behaviour.

Gulland (1987) criticizes the mortality-patchiness hypothesis on 2 grounds. First, he argues that the original observation from which the hypothesis was developed, the deviation between the observed $M$ of fish eggs and early-stage larvae and the $M$ predicted from Peterson \& Wroblewski's (1984) allometric model of $M$ for fish, was not due to the secondary action of spatial patchiness, but was due instead to a poor fit of the model to the data. Gulland claims that the weight exponent of $M$ for fish is about -0.5 , rather than the value of -0.25 used by Peterson \& Wroblewski and McGurk. Second, Gulland cites Brock \& Riffenburgh's (1960) theoretical model in support of the argument that patchiness reduces predation rather than increases it because a predator may encounter fewer prey if these are patchily distributed than if the prey are randomly distributed.

I dispute Gulland's first point on the grounds that the correlation between $W$-independent $M$ and patchiness for fish eggs and early-stage larvae remains valid even when a weight exponent with an absolute value greater than 0.25 is used to remove the effect of size. Furthermore, $M$ of fish eggs and early-stage larvae is even more highly correlated with patchiness when size is not factored out. I dispute Gulland's second point because Brock \& Riffenburgh's model is an oversimplified description of the relation between patchiness and mortality in fish of all life history stages. The model does not take into account the effect on survival of close-range predator evasion behaviour by schooling juvenile and adult fishes, and it does not take into account the effect on survival of the absence of this behaviour in fish eggs and early-stage larvae. The evasion behaviour associated with schooling may be as important a survival tactic as aggregation itself. Moreover, the model is entirely theoretical and has never been tested with field data.

Sources of data. Peterson \& Wroblewski (1984) assigned a value of -0.25 to the weight exponent of $M$ úsing biomass spectrum theory and data on the bioenergetics of fish. They did not calculate their exponent from the $M-W$ data itself. In order to compare empirical weight exponents for the pelagic ecosystem, fishes, and crustaceans with Peterson \& Wroblewski's estimate, linear regressions of $\ln M$ on $\ln W$ were calculated using the data in McGurk's (1986b) Table 1 and Appendix. The invertebrates Illex illecebrosus and 
Pleurobrachia bachei were excluded in order to produce an all-crustacean sub-group. Values of $M$ for pelagic bacteria of the Belgian coastal zone reported by Servais et al. (1985) were included in order to expand the $W$ scale to cover a larger range of the pelagic community. A single estimate of the average $W$ of a bacterium was calculated as $1.2 \times 10^{-13} \mathrm{~g}$ by assuming a cell volume of $0.6 \mathrm{\mu m}^{3}$ (Fenchel 1986), a density of $1 \mathrm{~g}$ $\mathrm{cm}^{-3}$, and a dry weight/wet weight ratio of $1: 5 . W$ of the school shark Galeorhinus australis was corrected to $1.1 \times 10^{4} \mathrm{~g}$ from the value of $1.1 \times 10^{5} \mathrm{~g}$ that was shown in the Appendix and $M$ of Paracalanidae spp. (pelagic crustaceans) was corrected to $5.2 \times 10^{-2} \mathrm{~d}^{-1}$ from $5.2 \times 10^{-7} \mathrm{~d}^{-1}$.

Both predictive and functional regressions (Ricker 1973, Jensen 1986) were calculated in order to show that the weight exponent of $M$ may depend strongly on the type of regression used to calculate it. Functional regressions are the best estimate of the central tendency of a relation when both variables are measured with the same amount of error, but predictive regressions are best when the dependent variable has been measured with much more error than the independent variable. Functional regressions always have higher slopes than predictive regressions. Therefore, as a conservative assumption, functional regressions were used to examine the effect of using an exponent other than -0.25 to factor out size from $M$.

Results. The slope ( $\pm 1 \mathrm{SE}$ ) of the functional regression for the entire data set, bacteria to whales, was $-0.301 \pm 0.011 \mathrm{~d}^{-1}$ (Table 1), which was lower than the functional slope $( \pm 1 \mathrm{SE}$ ) for the data set excluding the bacteria, $-0.343 \pm 0.011 \mathrm{~d}^{-1}$. The slope of the predictive regression for the entire data set was -0.26 $\pm 0.011 \mathrm{~d}^{-1}$. This result suggests that the estimate of the ecosystem slope depends strongly on the distribution of data along the $W$ scale, and on the distribution of error between the 2 variables. In this case, the estimates of the ecosystem slope tend to approach the values peculiar to large, easily sampled organisms such as larval, juvenile and adult fish because more than $90 \%$ of the data fell within the $10^{-5}$ to $10^{7} \mathrm{~g} \mathrm{~W}$ range. This argument depends partly on the validity of Servais et al.'s (1985) estimates of bacterial $M$. These were verified by comparing them with field estimates of growth rates of aquatic bacteria, since stable bacterial biomass can only be maintained if growth and mortality balance each other. Field estimates of daily growth rate of aquatic bacteria reported by Moriarty (1986) were plotted against $W$ in Fig. 1. The ranges of daily bacterial growth rate bracket Servais et al.'s estimates of $M$, thereby supporting them.

The functional slopes ( \pm 1 SE) for fish, $-0.397 \pm$ $0.010 \mathrm{~d}^{-1}$, and for crustaceans, $-0.537 \pm 0.082 \mathrm{~d}^{-1}$, were both significantly ( $p<0.05$ ) higher than the slope for the entire data set (bacteria to whales). The predictive slopes ( $\pm 1 \mathrm{SE}$ ) for fish and crustaceans were $-0.375 \pm 0.010$ and $-0.401 \pm 0.082 d^{-1}$, respectively. The crustacean slopes were significantly higher than the fish slopes. This analysis supports Gulland's assertion that the weight exponent of $M$ for fish is higher than -0.25 , but it does not support Gulland's assertion that the exponent is about -0.5 .

The use of the weight exponent of $M$ for fishes does not invalidate the mortality-patchiness hypothesis, as Gulland claimed. The ratio of the observed $M$ of pelagic fish eggs and early-stage larvae to $M$ predicted by the functional allometric equation for fish, $M_{F}$ (Table 1), is highly correlated with the geometric mean patchiness, $p$, of the fish eggs and early-stage larvae. The functional regression of the ratio $M / M_{\mathrm{F}}$ on $p$ is

$$
M / M_{\mathrm{F}}=0.33+0.17 p
$$

and the standard error of the slope is 0.03 . The predictive version of Eqn (1) has an $r$ of 0.56 and a $p$ of 0.009 .

The scatter of data about Eqn (1) may be caused in part by the effects of variables other than dry weight and patchiness. Pauly (1980) reported a significant and

Table 1. Linear regressions of $\ln M$ on $\ln W$ for pooled and separate taxa and ecological groups of marine pelagic organisms

\begin{tabular}{|c|c|c|c|c|c|c|c|}
\hline Taxon/group & $\begin{array}{l}\text { Regression } \\
\text { type }\end{array}$ & Slope & $\begin{array}{l}\text { SE of } \\
\text { Slope }\end{array}$ & Intercept & $\mathrm{n}$ & $I^{*}$ & $\mathrm{p}$ \\
\hline \multirow{2}{*}{$\begin{array}{l}\text { Bacteria, crusta- } \\
\text { ceans, fish and } \\
\text { whales }\end{array}$} & Functional & -0.301 & 0.011 & -4.944 & 198 & 1.00 & $<0.0001$ \\
\hline & Predictive & -0.260 & 0.011 & -4.850 & 198 & 0.87 & $<0.0001$ \\
\hline \multirow{4}{*}{$\begin{array}{l}\text { Crustaceans, fish } \\
\text { and whales } \\
\text { Fish }\end{array}$} & Functional & -0.343 & 0.011 & -4.883 & 193 & 1.00 & $<0.0001$ \\
\hline & Predictive & -0.310 & 0.011 & -4.830 & 193 & 0.90 & $<0.0001$ \\
\hline & Functional & -0.397 & 0.010 & -4.778 & 165 & 1.00 & $<0.0001$ \\
\hline & Predictive & -0.374 & 0.010 & -4.754 & 165 & 0.94 & $<0.0001$ \\
\hline \multirow[t]{2}{*}{ Crustaceans } & Functional & -0.537 & 0.082 & -8.860 & 21 & 1.00 & 0.0001 \\
\hline & Predictive & -0.401 & 0.082 & -7.356 & 21 & 0.75 & 0.0001 \\
\hline
\end{tabular}


Fig. 1. Plot of instantaneous daily natural mortality rates: $M$, on dry weight, $W$, for marine pelagic organisms. Data for fish, crustaceans and whales from McGurk (1986b); data for bacteria from Servais et al. (1985). Vertical bars are ranges of growth rates of natural populations of aquatic bacteria from Moriarty (1986). Line A is the functional regression of $\ln M$ on $\ln W$ for all organisms (bacteria to whales): $M=7.13 \times 10^{-3}$ $W^{-0.301}$. Line $\mathrm{B}$ is the functional regression of $\ln M$ on $\ln W$ for fish only: $M=8.41 \times 10^{-3}$ $W^{-0.397}$. Line $\mathrm{C}$ is the functional regression for pelagic crustaceans only: $M=1.42 \times 10^{-4}$ $W^{-0.537}$

positive correlation between the $M$ of adult fishes and mean annual sea surface temperature. Therefore, by analogy, some of the residual ( $W$-independent) variation in $M$ of fish eggs and early-stage larvae may be explained by temperature. In order to test this hypothesis, mean field water temperatures were taken from the literature sources from which the estimates of $M$ were taken (Table 2). Exploratory regression analysis showed that patchiness and temperature, $T$, were significantly and positively correlated. The functional regression of $\ln p$ on $T$ was

$$
\ln p=-0.809+0.175 T
$$

and the standard error of the slope was 0.048 . The predictive regression had an $\mathrm{r}$ of 0.64 and a p of 0.002 . However, neither $M / M_{\mathrm{F}}$ nor $\ln \left(M / M_{\mathrm{F}}\right)$ were significantly correlated with $T(\mathrm{p}=0.100$ and 0.053 , respectively). Stepwise multiple regressions of $M / M_{\mathrm{F}}$ on $p$ and $T$, and of $\ln \left(M / M_{\mathrm{F}}\right)$ on $\ln p$ and $T$, rejected $T$ as a significant variable. Therefore, the hypothesis that temperature is a secondary factor influencing mortality is not supported by evidence. The possibility that the correlation between mortality and patchiness in fish embryos is the product of a more fundamental correlation between mortality and temperature is also rejected.

The estimates of $M$ in Tabie 2 (and $\ln M$ ) were regressed on $p, T$ and $W$ and on $\ln p, T$ and $\ln W$, both separately and together, in order to produce an equation that could predict $M$ without any reference to $M-W$ allometry of the larger fish taxon. It was found that $\ln M$ was highly correlated with $\ln p$; the functional regression was

$$
M=-3.255+1.090 \ln p,
$$

and the standard error of the slope was 0.227 . The predictive regression had an $\mathrm{r}$ of 0.74 and a $\mathrm{p}$ of 0.0001 .
Neither $M$ nor $\ln M$ were significantly correlated with $T$ $(\mathrm{p}=0.21)$. The greatest amount of variance in $\ln M$ was explained by a multiple regression of $\ln M$ on $\ln p$ and $\ln W$,

$$
\ln M=-5.368+0.540 \ln p-0.387 \ln W
$$

where $r=0.83, p=0.0002$, and the standard errors of the coefficients for $\ln p$ and $\ln W$ were 0.173 and 0.139 , respectively.

Discussion. The weight exponents of $M$ calculated above fall within the range of exponents previously reported for 2 ecological numbers that are similar to $M$ : the production/biomass ratio, $\mathrm{P} / \mathrm{B}$, and the intrinsic rate of natural increase, $I_{\mathrm{m}}$. In a steady-state system a $\mathrm{P} / \mathrm{B}$ ratio is equivalent to $M$ because it is that fraction of the production excess to the needs of maintaining a stable biomass. In a steady-state system $r_{\mathrm{m}}$ must equal $M$ in order to maintain a stable population size. Dickie et al.'s (1987) reanalysis of Banse \& Mosher's (1980) data on the $\mathrm{P} / \mathrm{B}$ ratios of aquatic invertebrates and fish showed that the weight exponent of $\mathrm{P} / \mathrm{B}$ for the pooled data was about -0.2 . Schwinghamer et al. (1986) found a similar exponent, -0.208 , for the $\mathrm{P} / \mathrm{B}$ ratios of marine benthic organisms. Both Banse \& Mosher and Schwinghamer et al. found that most taxa (i.e. crustaceans, fishes) or ecological groups (i.e. macrofauna, meiofauna) had weight exponents ranging from -0.3 to -0.4 , significantly higher than the community exponents. The one exception was an exponent of -0.26 calculated by Banse \& Mosher for fish. Fenchel (1974) found that the weight exponent of $r_{\mathrm{m}}$ was about -0.275 in unicells, heterotherms, and homoiotherms. Blueweiss et al. (1978) reanalysed Fenchel's data as a single group with a weight exponent of -0.26 .

In summary, the community or ecosystem weight exponents of $M, \mathrm{P} / \mathrm{B}$ and $r_{\mathrm{m}}$ fall within the range -0.2 to -0.275 and the exponents of taxa and ecological 
Table 2. Natural mortality, $M$, dry weight, $W$, mean spatial patchiness, $p$, and mean water temperature, $T$, of pelagic fish eggs and larvae. Sources of data are listed in McGurk (1986b: Table 1)

\begin{tabular}{|c|c|c|c|c|c|}
\hline Species & Area & $M\left(d^{-1}\right)$ & $W(\mathrm{~g})$ & $p$ & $T\left({ }^{\circ} \mathrm{C}\right)$ \\
\hline \multicolumn{6}{|l|}{ Fish eggs } \\
\hline \multirow[t]{2}{*}{ Chrysophrys auratus } & Hauraki Gulf, New Zealand & 1.01 & $8.4 \times 10^{-5}$ & 6.75 & 19.0 \\
\hline & & 0.30 & $8.4 \times 10^{-5}$ & 5.00 & 19.0 \\
\hline Melanogrammus aeglefinus & Browns Bank, Nova Scotia & 0.38 & $3.2 \times 10^{-4}$ & 3.32 & 5.0 \\
\hline Pleuronectes platessa & English Channel & 0.08 & $8.4 \times 10^{-4}$ & 1.00 & 9.0 \\
\hline Sardinops sagax & S California coast & 0.31 & $5.2 \times 10^{-4}$ & 22.42 & 15.0 \\
\hline \multirow[t]{2}{*}{ Scomber scombrus } & NE Atlantic coast, USA & 0.13 & $1.4 \times 10^{-4}$ & 6.32 & 11.0 \\
\hline & & 0.88 & $1.4 \times 10^{-4}$ & 12.74 & 11.0 \\
\hline \multicolumn{6}{|l|}{ Fish larvae } \\
\hline Archosargus rhomboidalis & Terminos Lagoon, SE Mexico & 0.43 & $9.2 \times 10^{-5}$ & 9.80 & 26.0 \\
\hline \multirow[t]{4}{*}{ Clupea harengus pallasi } & Barkley Sound, Vancouver Is. & 0.09 & $1.6 \times 10^{-3}$ & 1.86 & 9.0 \\
\hline & & 0.09 & $1.6 \times 10^{-3}$ & 2.13 & 11.0 \\
\hline & & 0.06 & $1.6 \times 10^{-3}$ & 1.86 & 9.0 \\
\hline & & 0.31 & $1.6 \times 10^{-3}$ & 1.77 & 10.0 \\
\hline Engraulis mordax & S California coast & 0.22 & $7.0 \times 10^{-4}$ & 16.79 & 15.0 \\
\hline Pleuronectes platessa & English Channel & 0.08 & $7.5 \times 10^{-4}$ & 1.00 & 9.0 \\
\hline Sardinella aurita & Senegal-Gambia coast & 0.45 & $3.6 \times 10^{-4}$ & 11.39 & 23.0 \\
\hline Scomber scombrus & NE Atlantic coast, USA & 0.35 & $3.0 \times 10^{-4}$ & 5.38 & 18.0 \\
\hline \multirow{3}{*}{ Sebastes spp. } & Flemish Cap, NW Atlantic & 0.05 & $3.8 \times 10^{-3}$ & 3.53 & 8.0 \\
\hline & & 0.05 & $3.8 \times 10^{-3}$ & 2.43 & 6.0 \\
\hline & & 0.07 & $3.8 \times 10^{-3}$ & 1.05 & 8.0 \\
\hline Trachurus symmetricus & S California coast & 0.78 & $4.0 \times 10^{-4}$ & 15.83 & 16.0 \\
\hline
\end{tabular}

groups are within the range -0.3 to -0.4 . I conclude that a weight exponent of -0.25 is appropriate for the modelling of $M$ in pelagic ecosystems. It was, therefore, an appropriate exponent for the analysis of the mortality-patchiness interaction.

In retrospect it is clear that an analysis of the allometry of $M$ for the pelagic ecosystem or for the entire fish taxon was not strictly necessary in order to demonstrate a correlation between $M$ and patchiness in fish eggs and larvae. Although $W$ explained $94 \%$ of the variance in $M$ for all fishes combined (Table 1), regression Eqns (3) \& (4) show that $M$ of fish eggs and early-stage larvae is more highly correlated with mean patchiness than it is with mean weight.

It is interesting to note that the predictive weight exponent of $M$ for the entire fish taxon, $-0.374 \pm$ 0.010 , is very close to the weight exponent of $M$ in the multiple regression of $\ln M$ on $\ln p$ and $\ln W$ for fish eggs and early-stage larvae (Eqn 4), $-0.387 \pm 0.139$. This indicates that the higher correlation coefficient of Eqn (4), 0.83, compared to that of Eqn (1), 0.56, is not due to differences in the exponents but to differences in the intercept of the regressions. The lower intercept of Eqn (4), -5.368 , provides a better fit to the $M$ of fish eggs and larvae than the higher intercept of the regression for the entire fish taxon, -4.754 .

The fact that the patchiness of fish eggs and larvae is significantly higher for species that spawn in warm water than for species that spawn in colder water (Eqn 2) is most likely due to the fact that temperature controls the duration of fish egg and larval stages (see review by McGurk 1984). Therefore, eggs and larvae that develop in cold water tend to spend more time in any developmental stage than eggs and larvae that develop in warmer water. Thus, populations of coldwater eggs and larvae tend to be older, on average, than populations of warm-water eggs and larvae. Older fish eggs and larvae are less patchy than younger eggs and larvae because patchiness decays rapidly with age due to the turbulent diffusion of the upper water layers (Smith 1973, Hewitt 1981, McGurk 1987).

This relationship between temperature, the average age of a population of fish embryos, and the spatial patchiness of the embryos explains why $M$ is independent of temperature in these life history stages. Temperature does not control patchiness or the rate at which patchiness decays with age, thus temperature does not affect the vulnerability of patchy embryos to predators. However, temperature controls the rate of development of an embryo and so it controls the duration of the period within which the interaction of mortality and patchiness operates.

Gulland's second major criticism of the mortalitypatchiness hypothesis is that spatial patchiness should reduce predation on fish eggs and early-stage larvae, rather than increase it, for some of the same reasons that patchiness is believed, on theoretical grounds, to reduce predation on schooling juvenile and adult fish. There is little doubt that schooling or shoaling of fish evolved, in part, as a defence against predators, but this is not its sole function. Schooling is also a foraging strategy (see reviews by Pitcher 1986a, b). To the best 
of my knowledge, there is no mathematical model yet available that combines the anti-predator and foraging functions of schooling. In the absence of such a model, one can only speculate about the possible relationships between $M$ and patchiness in juvenile and adult fishes. Brock \& Riffenburgh's (1960) model suggests that the $M$ of juvenile and adult fish may be inversely related to their spatial patchiness. This relationship has not yet been tested with field data, which is surprising when one considers that the model is over $15 \mathrm{yr}$ old.

A more important point for the purpose of this note is that the anti-predator function of schooling includes a second class of behaviour that occurs only when a predator encounters a school. This behaviour includes inspection of the predator by individual prey, rapid transfer of information about the predator across the school, and predator evasion by alternate compaction and flash expansion of the school (Pitcher 1986b). This second class of anti-predator behaviour may be as important to survival as the strategy of avoiding predator encounter through patchy distribution in space.

The second class of anti-predator behaviour is absent or poorly developed in fish embryos. Much experimental work reported by Bailey \& Yen (1983), Bailey (1984), Bailey \& Batty (1984), Folkvord \& Hunter (1986), Purcell et al. (1987) and others cited by these authors has demonstrated that early-stage fish larvae are highly vulnerable to attack by fish and invertebrate predators, and that the ability of a larva to escape attack increases rapidly with increasing size and stage of development. McGurk's (1986b) conceptual model of fish egg and early-stage larval mortality is based on this fact.

The central question in this matter is whether the advantages to fish embryos of avoiding predators by being patchily distributed outweighs the disadvantages of being discovered by a predator as a member of a patch. The theoretical arguments cited by Gulland predict that the former factor will outweigh the latter, but the field evidence on average $M$ and average patchiness supports the alternate hypothesis; that being in a patch reduces the survival of fish embryos.

The mortality-patchiness hypothesis is supported by other evidence. According to the logic described above the trajectory of $M$ with age for the earliest life stages of a cohort of fish should be correlated in direction and magnitude with the trajectory of patchiness with age of that cohort. Simultaneous measurements of $M$-at-age, patchiness-at-age and weight-at-age of field cohorts are not yet available. However, patchiness-age curves have been reported for the early life stages of 4 species of pelagic fish: Pacific sardine Sardinops sagax eggs (Smith 1973); northern anchovy Engraulis mordax and jack mackerel Trachurus symmetricus larvae (Hewitt 1981); and Pacific herring Clupea harengus pallasi larvae (McGurk 1987). All 4 curves have a similar pattern: relatively high patchiness at hatch that decays to a minimum level by Day 10 to 30 as the eggs or larvae disperse, followed in the larval stage by a rapid increase in patchiness as the late-stage larvae begin to congregate in schools. Pacific sardine eggs have the highest patchiness at any age: 60 points at hatch falling to 5 points at an age of $3 \mathrm{~d}$; followed by northern anchovy larvae: 10 points at hatch falling to 6 points

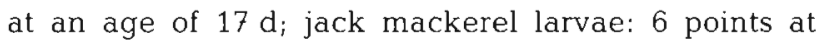
hatch falling to 4 at an age of $10 \mathrm{~d}$; and Pacific herring larvae: 3.8 points at hatch falling to 1.6 points at an age of $25 \mathrm{~d}$.

A recent field study of the egg and larval stages of jack mackerel by Hewitt et al. (1985) reported that $M$ declined from $5.46 \mathrm{~d}^{-1}$ at spawning to $1.82 \mathrm{~d}^{-1}$ at hatch and $0.27 \mathrm{~d}^{-1}$ at $20 \mathrm{~d}$ of age, a 20 -fold decline. Lo (1986) reported that the $M$ of northern anchovy declined from an average of $1.9 \mathrm{~d}^{-1}$ at spawning to $0.7 \mathrm{~d}^{-1}$ at hatch and $0.1 \mathrm{~d}^{-1}$ at $20 \mathrm{~d}$ of age, which is also a decline by a factor of 20 . Smith (1973) measured the $M$ of Pacific sardine eggs as a constant $0.31 \mathrm{~d}^{-1}$, which may reflect the fact that the duration of the egg stage is only $3 \mathrm{~d}$. It may be difficult to measure changes in $M$ over such a short period. McGurk (1986a) found that the $M$ of Pacific herring larvae was constant over a $30 \mathrm{~d}$ period and that it ranged from 0.06 to $0.31 \mathrm{~d}^{-1}$ with an average of $0.14 \mathrm{~d}^{-1}$.

The fact that 2 of the 3 species with high and rapidly decaying patchiness also have high and rapidly decaying $M$, and that the species with the lowest and flattest patchiness-age curve also has a low constant $M$, is interpreted as evidence in support of a causal relationship between $M$ and patchiness in pelagic fish larvae.

Starvation cannot account for the decay in egg or yolksac larval $M$ of jack mackerel and northern anchovy, although it may contribute to the $M$ of the post-yolksac larvae. The decay in the $M$ of eggs and yolksac larvae cannot be due to changes in weight because eggs and yolksac larvae do not grow in weight. Post-yolksac larvae would have to increase in dry weight by a factor of at least 2500 in $20 \mathrm{~d}$ in order for the observed changes in $M$ to be explained as the result of growth.

In summary, Brock \& Riffenburgh's (1960) model is too simple to be realistic. It does not take into account the roles of foraging and close-range anti-predator behaviour. It is still a solely theoretical model because its predictions have now yet been tested. In contrast, the mortality-patchiness model is rooted in experimentally-verified behaviour of fish embryos and it has testable predictions which are supported by field data. I conciude that the balance of the evidence supports the concept of a direct relationship between mortality and patchiness in fish eggs and early-stage larvae. 


\section{LITERATURE CITED}

Bailey, K. M. (1984). Comparison of laboratory rates of predation on five species of marine fish larvae by three planktonic invertebrates: effects of larval size on vulnerability. Mar. Biol. 79: 303-309

Bailey, K. M., Batty, R. S. (1984). Laboratory study of predation by Aurelia aurita on larvae of cod, flounder, plaice and herring: development and vulnerability to capture. Mar. Biol. 83: 287-291

Bailey, K. M., Yen, J. (1983). Predation by a carnivorous marine copepod, Euchaeta elongata, on eggs and larvae of the Pacific hake, Merluccius productus. J. Plankton Res. 5 : $71-82$

Banse, K., Mosher, S. (1980). Adult body mass and annual production/biomass relationships of field populations. Ecol. Monogr. 50: 355-379

Blueweiss, L., Fox, H., Kudzma, V., Nakashima, D., Peters, R., Sams, S. (1978). Relationships between body size and some life history parameters. Oecologia (Berl.) 37: 257-272

Brock, V., Riffenburgh, R. (1960). Fish schooling: a possible factor in reducing predation. J. Cons. int. Explor. Mer 25: 307-317

Dickie, L. M., Kerr, S. R, Boudreau, P. R. (1987). Size-dependent processes underlying regularities in ecosystem structure. Ecol. Monogr. (in press)

Fenchel, T. (1974). Intrinsic rate of natural increase: the relationship with body size. Oecologia (Berl.) 14: 317-326

Fenchel, T. (1986). The ecology of heterotrophic microflagellates. Adv. microb. Ecol. 9: 57-97

Folkvord, A., Hunter, J. R. (1986). Size-specific vulnerability of northern anchovy to predation by fishes. Fish. Bull. U. S. 84: 859-869

Gulland, J. A. (1987). Natural mortality and size. Mar. Ecol. Prog. Ser. 39: 197-199

Hewitt, R. (1981). The value of pattern in the distribution of young fish. Rapp. P.-v. Réun. Cons. int. Explor. Mer 178: 229-236

Hewitt, R. P., Theilacker, G. H., Lo, N. C. H. (1985). Causes of mortality in young jack mackerel. Mar. Ecol. Prog. Ser. 26: $1-10$

Jensen, A. L. (1986). Functional regression and correlation analysis. Can. J. Fish. Aquat. Sci. 43: 1742-1745

Lloyd, M. (1967). Mean crowding. J. Anim. Ecol. 36: 1-30

Lo, N. C. H. (1986). Modelling life-stage-specific instantane- ous mortality rates, an application to northern anchovy, Engraulis mordax, eggs and larvae. Fish. Bull. U. S. 84: 395-407

McGurk, M. D. (1984). Effects of delayed feeding and temperature on the age of irreversible starvation and on the rates of growth and mortality of Pacific herring larvae. Mar. Biol. 84: $13-26$

McGurk, M. D. (1986a). The role of starvation in the population dynamics of Pacific herring larvae. Ph. D. thesis, Univ. of British Columbia, Vancouver

McGurk, M. D. (1986b). Natural mortality of marine pelagic fish eggs and larvae: role of spatial patchiness. Mar. Ecol. Prog. Ser. 34: 227-242

McGurk, M. D. (1987). The spatial patchiness of Pacific herring larvae. Environ. Biol. Fish (in press)

Moriarty, D. J. W. (1986). Measurement of bacterial growth rates in aquatic systems from rates of nucleic acid synthesis. Adv. microb. Ecol. 9: 245-292

Pauly, D. $(1980)$. On the interrelationships between natural mortality, growth parameters, and mean environmental temperature in 175 fish stocks. J. Cons. int. Explor. Mer 39: 175-192

Peterson, I., Wroblewski, J. S. (1984). Mortality rate of fishes in the pelagic ecosystem. Can. J. Fish. Aquat. Sci. 41: $1117-1120$

Pitcher, T. J. (1986a). Functions of shoaling behaviour in teleosts. In: Pitcher, T. J. (ed.) The behaviour of teleost fishes. Croom Helm, London, p. 294-337

Pitcher, T. J. (1986b). Predators and food are keys to understanding fish shoals: a review of recent experiments. Naturaliste can. (Rev. Ecol. Syst.) 113: 225-233

Purcell, J. E., Siferd, T. D., Marliave, J. B. (1987). Vulnerability of larval herring (Clupea harengus pallasi) to capture by the jellyfish Aequorea victoria. Mar. Biol. 94: 157-162

Ricker, W E. (1973). Linear regressions in fishery research. J. Fish. Res. Bd Can. 30: 409-434

Schwinghamer, P., Hargrave, B., Peer, D., Hawkins, C. M. (1986). Partitioning of production and respiration among size groups of organisms in an intertidal benthic community. Mar. Ecol. Prog. Ser. 31: 131-142

Servais, P., Billen, G., Rego, J. V. (1985). Rate of bacterial mortality in aquatic environments. Appl. environ. Microbiol. 49: 1448-1454

Smith, P. E. (1973). The mortality and dispersal of sardine eggs and larvae Rapp. P.-v. Réun. Cons. int. Explor. Mer 164: 282-291 